\title{
Coping styles associated with heart failure outcomes: A systematic review
}

\author{
Lucinda J. Graven ${ }^{1}$, J oan S. Grant ${ }^{2}$, David E. Vance ${ }^{2}$, Erica R. Pryor ${ }^{2}$, Laurie Grubbs ${ }^{1}$, Sally \\ Karioth $^{1}$ \\ 1. College of Nursing, Florida State University, Tallahassee, Florida, USA. 2. School of Nursing, University of Alabama at \\ Birmingham, Birmingham, AL, USA.
}

Correspondence: Lucinda J. Graven. Address: College of Nursing, Florida State University, Tallahassee, Florida, USA. Email: Igraven@fsu.edu

Received: August 29, 2013

DOI : $10.5430 /$ jnep.v4n2p227
Online Published: January 1, 2014
Accepted: December 9, 2013

URL: http://dx.doi.org/10.5430/jnep.v4n2p227

\section{Abstract}

Background: The incidence of heart failure continues to rise in the United States, with more than 600,000 new cases diagnosed each year. The progressive nature of heart failure predisposes individuals to physical and psychological sequelae, including physical activity intolerance and depressive symptoms. Coping is beneficial in assisting individuals to live with heart failure. Evidence suggests that how individuals cope with heart failure may influence heart failure-related outcomes, such as psychological well-being, self-care, health-related quality of life, and mortality. Thus, a better understanding of coping styles can assist clinicians and researchers to develop interventions that improve heart failure outcomes.

Purpose: To provide a systematic review and synthesis of evidence regarding the influence of coping styles in HF. A conceptualization of coping commonly used in heart failure-related literature within the context of stress and cognitive appraisal of stress is described. In addition, this review will identify what is known about: (1) individual factors that influence coping styles in heart failure; (2) the influence of coping styles on heart failure-related outcomes; and (3) interventions that promote effective (e.g., problem-focused) coping in heart failure. Methodological issues associated with this empirical literature and implications for clinicians and research also were discussed.

Methods: This article provides a systematic review of current empirical evidence regarding the influence of coping styles on heart failure-related outcomes.

Results: This review of empirical literature revealed several factors that may influence coping style in individuals with HF, including co-morbidities, personality, illness knowledge and beliefs, and sense of coherence. Additionally, the use of problem-focused coping strategies was found to be related to positive HF outcomes, such as psychological well-being, enhanced self-care, and improved health-related quality of life. Whereas, the use of emotion-focused coping strategies was found to be associated with negative HF outcomes, such as psychological distress, decreased health-related quality of life, and increased HF-related mortality. Although limited, experimental work in this area suggests that problem-focused coping strategies may be beneficial in improving HF-related outcomes.

Conclusions: Effective coping aids the successful management of heart failure, specifically the management of associated physical symptoms and psychological sequelae that may result. Problem-focused strategies may be more beneficial than emotion-focused strategies in assisting individuals to cope with heart failure and improve heart failure outcomes, such as 
psychological well-being, self-care, and health-related quality of life. Conversely, emotion-focused strategies may negatively influence heart failure outcomes, such as psychological distress, decreased health-related quality of life, and heart failure-related mortality. Therefore, nurses should include problem-focused coping strategies in patient and family education. Research on the effectiveness of problem-focused strategies is sparse, thus more experimental studies, particularly longitudinal designs, is warranted to determine the efficacy of problem-focused interventions throughout the progression of heart failure.

\section{Key words}

Heart failure, Coping, Problem-focused coping, Emotion-focused coping, Outcomes

\section{I ntroduction}

Heart failure (HF) is a progressive disorder that results from the inability of the heart to effectively circulate blood throughout the body ${ }^{[1]}$. According to the American Heart Association (AHA) ${ }^{[2]}$, the incidence of HF continues to rise in the United States, with approximately 660,000 new cases diagnosed each year. Many of these individuals undergo treatment as outpatients ${ }^{[3]}$, with approximately 26.8 million individuals residing in outpatient settings ${ }^{[2]}$. However, living with HF is often stressful due to the progressive nature of physical symptoms (e.g., dyspnea, fatigue, edema, and activity intolerance) and complex treatment regimens (e.g., multiple medications, fluid and dietary restrictions, and daily weight monitoring) ${ }^{[1,4,5]}$.

In addition to physical symptoms, psychological sequelae are quite common in those with HF. For example, approximately $50 \%$ experience depressive symptoms ${ }^{[6]}$ secondary to the progression of physical symptoms, decreased functional ability, and social isolation ${ }^{[7-9]}$. Anxiety is also common, with as many as $45 \%$ experiencing this problem ${ }^{[9]}$. Therefore, clinicians who care for individuals with HF are challenged to identify strategies to effectively improve HF symptoms and the physical and psychological sequelae associated with this disease.

Coping can be beneficial in adapting to the psychological sequelae associated with multiple chronic illnesses ${ }^{[10-13]}$. In particular, evidence suggests that how individuals cope with HF may influence mortality rates, hospital readmission rates, psychological well-being, and self-care behaviors ${ }^{[14-18]}$. Therefore, a better understanding of coping styles in this clinical population can help clinicians and researchers develop interventions to improve HF outcomes.

This article presents a systematic review and synthesis of evidence regarding the influence of coping styles in HF. A conceptualization of coping commonly used in the HF-related literature is described. Research questions posed were the following: 1) What individual factors influence coping styles in HF? 2) How do coping styles influence HF outcomes? 3) What interventions promote effective (e.g., problem-focused) coping in HF? Methodological issues associated with this empirical literature and implications for clinicians and research also were discussed.

\section{Definitions and concepts}

\section{Stress, appraisal, and coping}

Stress, appraisal of stressful events, and coping are interrelated concepts that must be defined and discussed in tandem (see Figure 1). Stress results from an imbalance between environmental demands (i.e., stressors) and resources available to meet those demands. Therefore, stress occurs when individuals appraise that a stressor exceeds resources available to them to cope with these environmental demands ${ }^{[19]}$. Stressors create an imbalance, affecting their physical and psychological well-being and require actions to restore stability ${ }^{[20]}$. 


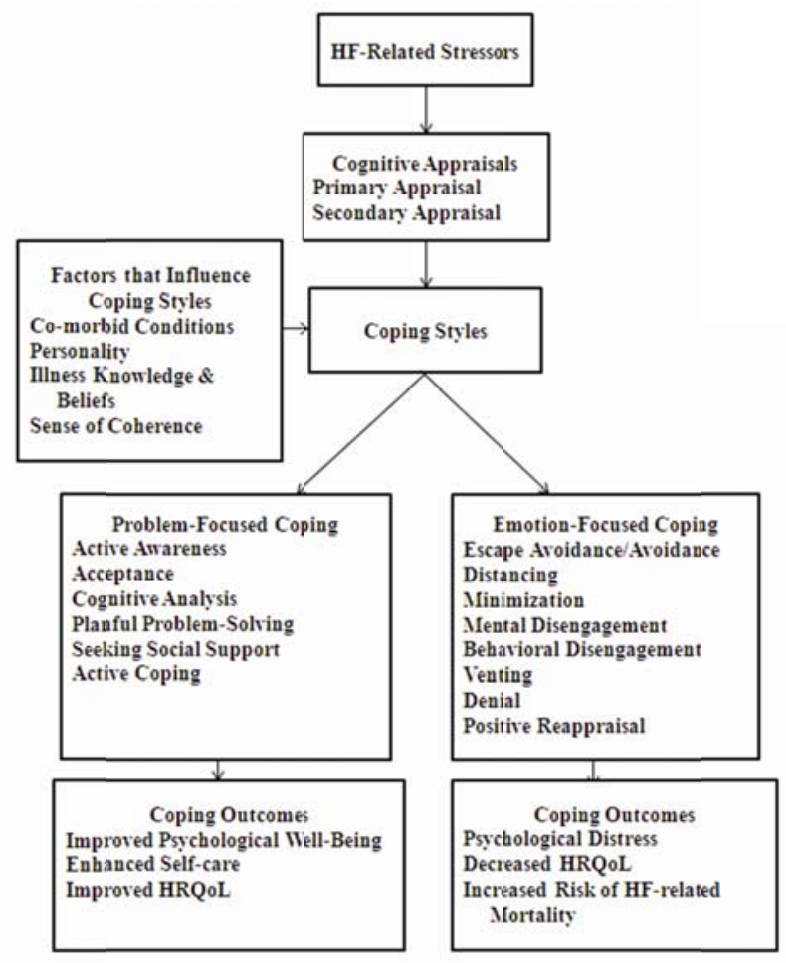

Figure 1. Conceptual overview of coping systems

Cognitive appraisal is the process used by individuals to evaluate the significance of stressful situations. Cohen ${ }^{[21]}$ describes two types of cognitive appraisal that are used by individuals to evaluate stressors. In primary appraisal, individuals judge the potential importance or significance of stressors (i.e., view them as stressful, challenging, irrelevant, etc.). In secondary appraisal individuals evaluate whether they possess the appropriate or necessary amount of resources to effectively deal with or manage stressors ${ }^{[21]}$. Thus, coping is a set of cognitive and behavioral activities used by individuals to manage internal (i.e., within individuals) and external (i.e., environmental) demands that exceed available resources ${ }^{[19]}$. Subsequently, efforts used to mediate primary and secondary appraisals generate coping outcomes, such as psychological well-being and functional status ${ }^{[22]}$.

Coping styles refer to ways in which individuals utilize coping resources and strategies to protect themselves from the negative effects of stressors. Coping styles used by individuals are often determined by how they appraise or evaluate stressful situations ${ }^{[23]}$. Lazarus and Folkman ${ }^{[19]}$ describe two coping styles: (1) problem-focused coping and (2) emotion-focused coping. Endler and Parker ${ }^{[24]}$ also refer to problem-focused coping as task-focused coping. Both coping styles encompass specific strategies that are meant to reduce stressors or emotions generated by internal and external demands.

Strategies associated with problem-focused coping are often used when individuals believe a situation is amenable to change. Conversely, emotion-focused coping strategies often are used when individuals feel stressors are less likely to be improved by their efforts ${ }^{[19]}$. Specific strategies associated with problem-focused coping include having an active awareness of stressors, acceptance, cognitive analysis ${ }^{[25]}$, planful problem-solving ${ }^{[25,26]}$, seeking social support, and active coping ${ }^{[19]}$ (see Table 1). These problem-focused strategies may be directed at either the environment or at the self. For example, individuals with HF may seek support from family as a means of coping with their HF-related treatment regimen, thus attempting to change their environment. Likewise, they may attempt to use problem-solving strategies to determine whether or not to seek treatment for increased symptoms of HF, thereby directing problem-focused strategies at themselves. 
Table 1. Problem and emotion focused strategies and descriptions

\begin{tabular}{|c|c|c|c|}
\hline \multicolumn{2}{|c|}{ Problem-Focused Coping Strategies } & \multicolumn{2}{|c|}{ Emotion-Focused Coping Strategies } \\
\hline $\begin{array}{l}\text { Active } \\
\text { Awareness }\end{array}$ & $\begin{array}{l}\text { Being actively aware, both physically and } \\
\text { mentally, of the stressful situation }\end{array}$ & $\begin{array}{l}\text { Escape } \\
\text { Avoidance/Avoi } \\
\text { dance }\end{array}$ & $\begin{array}{l}\text { Involves disengaging or staying away from } \\
\text { stressful situations and its behavioral and } \\
\text { cognitive/emotional consequences }\end{array}$ \\
\hline Acceptance & $\begin{array}{l}\text { Accepts the reality of the stressful } \\
\text { situation and attempts to deal with the } \\
\text { stressor }\end{array}$ & Distancing & $\begin{array}{l}\text { A remoteness in behavior; coolness of manner; } \\
\text { reserve }\end{array}$ \\
\hline $\begin{array}{l}\text { Cognitive } \\
\text { Analysis }\end{array}$ & $\begin{array}{l}\text { Internal efforts by individuals to manage } \\
\text { how they subjectively appraise situations } \\
\text { to understand them better, to solve } \\
\text { problems through logical analysis, or to } \\
\text { view situations from a unique perspective }\end{array}$ & Minimization & $\begin{array}{l}\text { A process of underestimating the importance and } \\
\text { relevance of a stressor }\end{array}$ \\
\hline $\begin{array}{l}\text { Planful } \\
\text { Problem- } \\
\text { Solving }\end{array}$ & $\begin{array}{l}\text { Actively thinking about how to deal with } \\
\text { stressors. Involves identifying and } \\
\text { defining stressors, generating potential } \\
\text { solutions, weighing alternative solutions } \\
\text { according to risks/benefits, choosing a } \\
\text { solution, and acting upon chosen solutions }\end{array}$ & $\begin{array}{l}\text { Mental } \\
\text { Disengagement }\end{array}$ & $\begin{array}{l}\text { A variety of activities (i.e., distraction, } \\
\text { daydreaming, escape through sleep or TV) that } \\
\text { distract individuals from thinking about the } \\
\text { behavioral dimension or goal that the stressor is } \\
\text { interrupting }\end{array}$ \\
\hline $\begin{array}{l}\text { Seeking } \\
\text { Social } \\
\text { Support }\end{array}$ & $\begin{array}{l}\text { Seeking out tangible, informational, } \\
\text { appraisal, and emotional support from } \\
\text { others (i.e., family, friends, and clinicians) }\end{array}$ & $\begin{array}{l}\text { Behavioral } \\
\text { Disengagement }\end{array}$ & $\begin{array}{l}\text { Reducing physical efforts to deal with a stressor } \\
\text { (i.e., giving up); withdrawing efforts from } \\
\text { attempting to achieve a goal that is associated with } \\
\text { the stressor }\end{array}$ \\
\hline $\begin{array}{l}\text { Active } \\
\text { Coping }\end{array}$ & $\begin{array}{l}\text { An active process involving steps to try to } \\
\text { remove, circumvent, or make a stressful } \\
\text { situation better }\end{array}$ & $\begin{array}{l}\text { Denial } \\
\text { Positive } \\
\text { Reappraisal }\end{array}$ & $\begin{array}{l}\text { Focusing on stressful situations and releasing the } \\
\text { associated emotions in a verbal or physical manner } \\
\text { An unconscious defense mechanism characterized } \\
\text { by a refusal to acknowledge painful situations, } \\
\text { thoughts, or feelings } \\
\text { A cognitive process in which individuals focus on } \\
\text { the good in a stressful situation rather than the } \\
\text { negative. }\end{array}$ \\
\hline
\end{tabular}

In contrast to problem-focused coping, emotion-focused coping involves strategies that are aimed at managing the emotional responses generated by stressors. Strategies associated with emotion-focused coping include escape-avoidance, distancing, minimization, mental and behavioral disengagement, venting, denial, and positive reappraisal ${ }^{[26]}$ (see Table 1). Whereas problem-focused strategies can be aimed at either the environment or at the self, emotion-focused strategies are commonly directed only to the self ${ }^{[23,27]}$. For example, those with HF often utilize mental and behavioral disengagement to cope with the progression of physical symptoms and physical activity intolerance ${ }^{[28,29]}$.

\section{Methodology}

A systematic review was conducted to provide a synthesis of the evidence regarding the influence of coping styles in HF. First a computerized search of the literature on coping styles in HF was conducted using PsycARTICLES, CINAHL, and PubMed databases. A variety of search terms were used for this review and included the following: "coping", "coping styles", "problem-focused", "emotion-focused", "social support", "problem-solving", and "heart failure". These words were combined with "outcomes", "psychological distress", "psychological well-being", "depression", "anxiety", "mortality", "health-related quality of life", "quality of life", "self-care", and "interventions". The search was limited to published reports after January 2000, with the exception of conceptual research, in an effort to obtain the most recent knowledge in this area. Reference lists from previous literature reviews were also examined to identify any relevant articles not previously identified in the computer search. Titles and abstracts of each article were reviewed to determine 
relevance to the review topic. Evidence from various fields, including psychology, nursing, medicine, and other healthrelated sciences were reviewed and synthesized.

Published articles that met the following criteria were included in the review: 1) the study was in English, 2) the study examined aspects of coping styles in HF, and 3) the articles were published between January 2000 and March 2013. Unpublished work (i.e., abstracts, student dissertations) were excluded from the review. The review was not restricted by study design and included qualitative, quantitative, and mixed methods studies. In an effort to reduce bias, review and analysis was conducted independently by two researchers. A comparison of findings was made and areas of disagreement were discussed until consensus of the findings was reached.

\section{Individual factors that influence coping styles in HF}

The progressive nature of HF necessitates the need for adequate coping; however, individual factors may influence how HF-related stressors are appraised and subsequently influence the coping style used. These factors include antecedents that are common in individuals with HF (e.g., co-morbidities and illness knowledge), as well as individual specific factors (e.g., personality and sense of coherence) that may influence the use of a specific coping style. The following section includes a discussion of these factors and how coping styles in those with HF may be influenced by these factors.

\section{Co-morbid conditions}

Most individuals with HF suffer from other chronic illnesses, which may decrease their ability to effectively cope with HF-related stressors. Findings from a large multi-site study examining 32,229 individuals admitted to the hospital with an exacerbation of HF provide insight into the prevalence of various co-morbid conditions experienced by this sample. In this study, hypertension was the largest co-morbidity (73\%) followed by coronary artery disease $(57 \%)$, diabetes mellitus $(44 \%)$, and renal insufficiency $(30 \%)^{[30]}$. However, other co-morbidities are plausible, given the average age of individuals with $\mathrm{HF}^{[2]}$. One of the most challenging stressors for individuals with co-morbid conditions involves polypharmacy. For those with co-morbidities, patients may take 10 or more medications ${ }^{[31,32]}$, thus potentially creating a stressful situation related to scheduling medications and managing polypharmacy side effects. This situation is compounded if individuals lack an understanding of their medications and how to self-adjust dosages based upon physician instructions, (e.g., diuretics) as the severity of HF symptoms increase (e.g., edema and weight gain) ${ }^{[33]}$.

Similarly, attempting to adhere to a HF-related dietary regimen becomes more stressful with the addition of dietary restrictions related to additional illnesses. Approximately, two-thirds of individuals with HF are trying to follow two or more different dietary regimens due to the presence of co-morbid conditions (e.g., diabetes mellitus) ${ }^{[34]}$. For example, individuals with HF and diabetes mellitus must limit both fluid intake and carbohydrates in order to comply with dietary recommendations associated with both illnesses, thus limiting the dietary choices available to them.

Monitoring symptoms of HF is also difficult due to the presence of co-morbidities. Individuals with lung disorders, diabetes mellitus, and renal disease may experience symptoms similar to those caused by HF, thus creating stress when individuals attempt to determine whether or not to self-adjust medication dosages or seek treatment for symptoms of $\mathrm{HF}^{[31]}$. Additional stressors associated with the presence of co-morbidities may be overwhelming for those with $\mathrm{HF}^{[8]}$, making it more difficult to effectively cope with HF-related stressors. Consequently, individuals with co-morbidities may be more likely to use emotion-focused coping strategies in an effort to deal with the emotions generated by these additional stressors. For example, the use of avoidance as a coping strategy (i.e., emotion-focused coping) has been reported by individuals with HF who also have multiple co-morbidities ${ }^{[17,35]}$. Yet, more research is needed to fully understand the influence of co-morbidities on coping in HF, as the amount of research in this area is sparse. 


\section{Personality}

Coping style may also be influenced by individuals' personality. Prior studies have indicated that personality influences how individuals cope with stressful situations ${ }^{[26,36,37]}$. Similarly, personality traits such as extraversion and neuroticism have been related to the use of specific emotion and problem-focused coping strategies, suggesting that personality plays a pivotal role in determining how individuals with HF cope with disease-related stressors. Specifically, in a study of 119 individuals with HF, those who reported higher levels of neuroticism were found to be more likely to use strategies associated with emotion-focused coping, such as denial, venting, and mental and behavioral disengagement. However, those who reported more extraversion tendencies were more likely to use strategies associated with problem-focused coping styles, such as positive reframing and acceptance ${ }^{[38]}$.

\section{Iness knowledge and beliefs}

Likewise, individuals' illness knowledge and perception of HF may influence coping style. Knowledge and beliefs about HF have been related to the use of emotion-focused coping strategies in two studies ${ }^{[39,40]}$. In one study of 35 women with $\mathrm{HF}$, greater illness knowledge was related to the use of low emotional expression (i.e., tendency to withhold emotions) ${ }^{[40]}$. Similarly, in a study of 146 individuals with HF, having negative beliefs about the illness was related to emotion-focused coping strategies such as denial and behavioral disengagement ${ }^{[39]}$.

\section{Sense of coherence}

Coping styles may also be influenced by individuals' sense of coherence, a view that recognizes the world as meaningful and predictable. For example, in a study of 80 individuals with HF, the use of emotion-focused coping strategies, such as denial, behavioral disengagement, venting, and self-blame was associated with a lower sense of coherence. Conversely, a high sense of coherence was associated with use of problem-focused coping strategies, particularly acceptance ${ }^{[41]}$.

\section{The influence of coping styles in HF}

Both coping styles, problem-focused and emotion-focused, are used by individuals with $\mathrm{HF}^{[15,27,29]}{ }^{\text {. Problem-focused }}$ coping strategies are generally viewed as more adaptive, while emotion-focused coping strategies are typically less adaptive to stressful situations ${ }^{[23]}$. While Lazarus and Folkman ${ }^{[19]}$ contend that effective coping requires both types of coping styles, findings suggest that the use of problem-focused coping strategies may be more effective in influencing

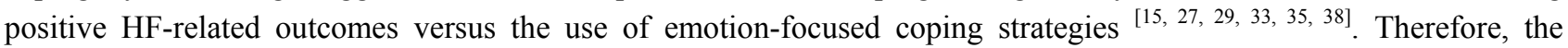
following discussion focuses first on problem-focused coping followed by emotion-focused coping and their effect on HF-related outcomes.

\section{Problem-focused coping and HF outcomes}

Several studies indicate that the use of problem-focused coping strategies are employed by those with HF to cope with everyday challenges (e.g., fatigue and dietary restrictions) associated with HF treatment, progression of physical symptoms, and decision-making regarding treatment ${ }^{[5,15,16,33,42,43]}$. Current evidence suggests that problem-focused coping strategies have a positive impact on several HF-related outcomes, including psychological well-being ${ }^{[27,29,44,45]}$, self-care ${ }^{[42,46]}$, and quality of life ${ }^{[46-48]}$. Thus, the following HF outcomes are reviewed in more detail.

Psychological well-being. The influence of coping on psychological distress, primarily depressive symptoms and anxiety, has been examined in several studies. Eight studies (five correlational and three qualitative), examined the influence of problem-focused coping strategies, such as seeking social support and planful problem-solving, on psychological well-being in individuals with HF. These studies indicated that the use of problem-focused coping strategies was related to decreases in psychological distress ${ }^{[8,27,29,38,42,44-46]}$. For example, in a study of 75 outpatients, those who reported seeking social support and planful problem-solving also reported fewer depressive symptoms ${ }^{[27]}$. Similarly, acceptance, as a coping strategy, was also related to psychological well-being (i.e., decreased depressive symptoms) ${ }^{[29,44]}$. 
Furthermore, evidence suggests that decreased use of problem-focused coping strategies has a negative influence on psychological well-being. For example, in a study of 222 outpatients, increases in psychological distress (i.e., depressive symptoms) were related to a decreased use of problem-focused strategies (e.g., decreased acceptance and problemsolving) ${ }^{[29]}$.

Self-care. Problem-focused coping strategies have also been found to enhance HF self-care in several studies. Thirteen studies (eight correlational, two qualitative, one mixed methods, one random control trial, and one secondary analysis) investigated the influence of problem-focused coping strategies on self-care in those with HF, yet findings were not congruent among the studies ${ }^{[16,33,42,43,49-57]}$. Findings of ten studies suggested that strategies such as seeking social

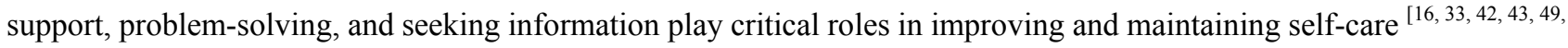
52, 53,55-57]. For instance, in a correlational study of 333 individuals by Gallagher and colleagues ${ }^{[16]}$, individuals with high levels of social support reported better self-care. Likewise, in a qualitative study of 26 individuals, problem-solving was reported to be beneficial in adjusting to HF-related functional limitations, such as using a shower chair and hand held spray nozzle to combat fatigue during a shower ${ }^{[42]}$.

Adherence to dietary and medication regimens were also associated with the use of problem-focused coping strategies, particularly the use of social support, in four studies ${ }^{[16,43,56,57]}$. In one study examining 74 individuals, family, particularly spouses, were instrumental in providing support with medication and dietary regimens ${ }^{[56]}$, while in another study of 134 individuals, perceived support was related to medication adherence ${ }^{[43]}$. Lastly, symptom assessment and management also appears to be influenced by problem-focused coping strategies, particularly through the incorporation of social support and use of problem-solving skills ${ }^{[33,56]}$. For example, in a study of 212 individuals hospitalized with HF, family (89.2\%) was reported to be the most common source of support, providing assistance with symptom assessment and treatmentseeking decision making ${ }^{[33]}$.

Conversely, three studies ${ }^{[50,51,54]}$ found that the use of problem-focused coping strategies, particularly the use of social support, did not significantly enhance self-care in individuals with HF. For example, in a study of 66 individuals, the use of social support was not found to be a significant predictor of self-care ${ }^{[50]}$. These findings were consistent with that of its parent study ${ }^{[54]}$, as well as those of Heo and colleagues ${ }^{[51]}$.

Health-related quality of life. Health-related quality of life (HRQoL) is a subjective multi-dimensional concept that is dynamic and includes three domains that influence individuals' perception of their well-being, including physical, social, and psychological domains ${ }^{[58,59]}$. Graven and Grant ${ }^{[60]}$ reported on sixteen studies (12 correlational and four qualitative) that examined the influence of coping styles and related strategies on HRQoL in individuals with HF, with 13 of these studies investigating coping styles and psychological HRQoL, two studies examining coping styles and physical HRQOL, and one study on both psychological and physical HRQOL. Evidence from nine of these studies suggests that HRQoL is enhanced with the use of problem-focused coping strategies, specifically psychological and physical domains ${ }^{[60]}$. Seven of those studies indicated that psychological HRQoL is positively influenced when problem-focused strategies, such as action/acceptance, planful problem-solving, and seeking social support are used ${ }^{[8,27,29,42,45,46]}$. For instance, in a study of 202 outpatients with HF, active coping was negatively related to depressive symptoms, thereby influencing the psychological domain of HRQoL ${ }^{[45]}$. Subjective well-being, a similar concept, was also found to be related to coping styles in a study of 60 individuals, with higher subjective well-being related to the use of problem-focused (i.e., task-focused) coping strategies ${ }^{[61]}$.

Two studies examined the relationship between coping styles and physical HRQoL, specifically the influence of coping styles on symptom status and management ${ }^{[14,47]}$. Findings from these studies suggest that the use of problem-focused strategies influences individuals' symptoms and their response to symptoms, thus enhancing the physical domain of HRQoL. For example, in one study of 58 outpatients, the use of problem-focused coping (e.g., action/acceptance) was 
related to the experience of less physical symptoms ${ }^{[14]}$, while in another study of 20 participants, social support, as a problem-focused coping strategy, was used to adapt to the progression of physical symptoms ${ }^{[47]}$.

\section{Emotion-focused coping and HF outcomes}

Individuals with HF use emotion-focused strategies, such as escape-avoidance, behavioral and mental disengagement, denial, and venting as a means of coping with the emotions that accompany HF-associated life changes, such as activity intolerance and social isolation ${ }^{[15,27-29]}$. The complexity of treatment regimens and progressive nature of HF is stressful ${ }^{[5,47,62]}$; therefore, individuals may use these strategies to cope with emotional responses that occur in HF. However, the use of emotion-focused coping strategies have been related to negative HF outcomes, specifically psychological distress (i.e., depressive symptoms and anxiety) ${ }^{[15,27-29,38,39,63,64]}$, decreased HRQoL ${ }^{[11,14]}$, and HF-related mortality ${ }^{[17,35]}$.

Psychological distress. Findings of ten studies (nine correlational and one qualitative) indicated that psychological distress, particularly depressive symptoms and anxiety, are related to the use of emotion-focused coping strategies, such as escape-avoidance, behavioral and mental disengagement, venting, self-blame, and denial ${ }^{[8,11,15,27-29,38,44,63,64]}$. For example, in a study of 84 individuals, avoidance was found to be a predictor of anxiety and depression ${ }^{[15]}$. Similarly, denial and self-blame were found to be predictors of depression in a study of 80 individuals ${ }^{[28]}$. However, qualitative findings from a study of 10 individuals with a self-reported history of current or past depressive symptoms, suggest that the use of emotion-focused strategies, such as distraction and mental disengagement, may actually assist individuals in coping with depressive symptoms and improve their outlook on life. In this study, participants described these strategies as having a positive influence on their psychological well-being and assisting in decreasing their depressive symptoms ${ }^{[8]}$.

Health-related quality of life. Twelve studies examined the influence of emotion-focused coping on HRQoL, specifically psychological and physical domains ${ }^{[8,11,14,15,27-29,38,44,62-64]}$. Ten (nine correlational and one qualitative) of these studies investigated the influence of emotion-focused strategies on the psychological domain of HRQoL, one correlational study examined the physical domain, and one correlational study investigated both psychological and physical domains. Findings from these studies primarily suggest that psychological HRQoL is negatively influenced by the use of emotion-focused coping strategies, such as self-distraction, denial, self-blame, and behavioral and mental disengagement. Specifically, emotion-focused coping was related to increases in psychological distress (i.e., depressive symptoms and anxiety) ${ }^{[11,15,27-29,38,44,62-64]}$. For example, Trivedi and colleagues ${ }^{[29]}$ reported that in a study of 222 participants, behavioral disengagement, denial, and venting was related to increases in depressive symptoms. Also, the use of emotion-focused strategies was associated with less subjective well-being in a study of 60 individuals ${ }^{[61]}$. Additionally, findings suggest emotion-focused coping strategies influence the physical domain of HRQoL. Although these findings are limited, one study of 58 participants suggests that strategies, including focusing solely on symptoms and distraction, were related to increases in the physical symptoms of $\mathrm{HF}^{[14]}$.

Mortality. Lastly, HF-related mortality also appears to be influenced by use of emotion-focused strategies. Although work in this area is sparse, longitudinal data suggest that use of emotion-focused coping strategies may actually increase an individual's risk of HF-related mortality. In a six-year longitudinal study using proportional hazard models, the use of behavioral disengagement was associated with an increased risk of mortality in 119 individuals, both at baseline ${ }^{[35]}$ and six-years later ${ }^{[17]}$. Although limited, this evidence suggests that how one copes with HF-related stressors may influence life expectancy.

\section{Problem-focused coping interventions and HF outcomes}

Studies are limited that investigate the efficacy of problem-focused coping interventions in those with HF. These studies have focused primarily on stress management techniques, including relaxation techniques and Mindfulness Based Stress 
Reduction (MBSR) techniques, a meditative practice that involves present awareness of mental processes and physical states. These stress management techniques are considered problem-focused strategies because they promote an active awareness of stressors ${ }^{[65,66]}$ within individuals. Primary HF-related outcomes investigated in these experimental studies ${ }^{[67-69]}$ have focused on psychological well-being, physical/functional status, and quality of life.

Stress management and relaxation interventions appear to be beneficial in promoting stress reduction and aid in the coping process. Stress management and relaxation training are psychosocial practices that help to decrease sympathetic stimulation and have been useful in both primary and secondary prevention of coronary artery disease ${ }^{[65]}$. Luskin and colleagues ${ }^{[67]}$ found that stress management techniques improved levels of depression $(p=.02)$, perceived stress $(p=.001)$, functional status $(p<.001)$ and emotional status $(p=.02)$ in a diverse sample of 33 participants. These findings were supported in a larger study by Sullivan and colleagues ${ }^{[68]}$, in which 217 individuals receiving an intervention using MBSR ${ }^{[66]}$, reported decreases in depression $(p<.05)$ and anxiety $(p<.05)$ over a 12-month period. However, Sullivan and colleagues ${ }^{[68]}$ found that quality of life only improved at the 12-month follow-up period, suggesting that use of MBSR may be more beneficial as a long-term coping strategy versus a short-term strategy. Conversely, Yu and colleagues ${ }^{[69]}$ investigated the effects of relaxation therapy, a behavioral therapy that promotes the release of bodily tensions and positive thoughts as a means of coping with stressful situations ${ }^{[70]}$. Using a sample of 121 Chinese, Yu and colleagues ${ }^{[69]}$ found that psychological well-being $(p=.01)$ and HRQoL $(p=.02)$ improved in those participating in the four month therapy program.

\section{Methodological issues: Strengths and weaknesses}

The majority of work in this field is a product of cross-sectional, correlational studies. While correlational studies have provided strong evidence for relationships between problem- and emotion-focused coping strategies and positive and negative HF outcomes, respectively ${ }^{[15,27,35,42,45,46,71]}$, a lack of longitudinal studies prevents an examination of the influence of coping and coping styles on HF outcomes over time. Further, knowledge of how individuals' coping needs and coping styles may change as HF progresses also is limited.

A limitation of most of these correlational studies was the lack of a conceptual/theoretical framework, although some studies ${ }^{[11,27,41]}$ did use the theoretical framework for coping by Lazarus and Folkman ${ }^{[19]}$. Additionally, several studies investigating coping and psychological distress failed to differentiate between depressive symptoms and depression, even though differences in these terms exist ${ }^{[27-29,38,44,45,63,64]}$. Similarly, anxiety is closely related to depressive symptoms and overlap of symptoms is plausible ${ }^{[72]}$; yet many studies did not account for this similarity ${ }^{[27-29,38,44,45]}$.

The majority of correlational studies used valid and reliable instruments. For example, Kristofferzon and colleagues ${ }^{[11]}$ used the Jalowiec Coping Scale, with internal consistency $>0.80$ and Carels ${ }^{[44]}$ used the Ways of Coping Questionnaire, with internal consistency coefficients $>0.80$. However, one instrument with consistently low internal consistency coefficients (i.e., the Coping Orientation for Problem Experiences) was used in some studies ${ }^{[28,38]}$.

While more experimental work is needed to confirm findings of existing experimental studies to strengthen the inference of causality ${ }^{[73]}$, studies cited in this review ${ }^{[67-69]}$ did add to the body of knowledge regarding the influence of coping interventions on coping styles in HF and illustrate that stress management techniques may be a beneficial problem-focused coping strategy in this population. However, intervention periods in these studies were brief (i.e., eight to 12 weeks) and follow-up periods were short (i.e., $\leq$ one year). Additionally, one experimental study used a pre/post design without also assessing intervening process variables during the intervention which were thought to contribute to outcome variables; so it is questionable as to whether the intervention actually caused the effect in that study ${ }^{[67]}$. Furthermore, no experimental studies addressed steps taken to enhance intervention fidelity, nor did these studies use a conceptual/theoretical framework to guide the intervention. Despite convenience sampling, random assignment was reported to be used in these studies to 
balance key characteristics of participants in all but one of the experimental studies ${ }^{[67]}$. Likewise, valid and reliable instruments were used to measure outcome variables in these experimental studies.

A limitation noted with both cross-sectional and experimental studies reviewed is that samples were not characteristic of national HF statistics. Current statistics indicate that the incidence of HF is most common in African American males over the age of 65 , followed by Caucasian males ${ }^{[2,74]}$, primarily due to increased rates of hypertension. However, the majority of cross-sectional studies used samples comprised primarily of Caucasian males, while samples used in experimental studies were mostly Caucasian women, with the exception of two studies. Yu and associates ${ }^{[69]}$ used an all Chinese sample while Luskin and colleagues ${ }^{[67]}$ included a diverse sample of approximately half Caucasian and half African American, Asian, and Latino participants. This lack of sample diversity among the body of literature examining coping styles in HF limits the generalizability of findings to a larger population of individuals with $\mathrm{HF}^{[75]}$.

Given these strengths and weaknesses, the current knowledge suggests that effective coping is a vital component in maintaining physical and mental well-being in individuals with HF. Problem-focused coping strategies appear to be related to better HF outcomes versus emotion-focused coping strategies. The use of social support, particularly family support, as a problem-focused coping strategy is pivotal in influencing positive HF outcomes (i.e., psychological wellbeing, self-care, and HRQoL). Additionally, evidence suggests that stress management techniques, such as MBSR and relaxation therapy, may be effective problem-focused coping strategies; however, the limited number of studies prevents the inference of causality.

\section{I mplications for clinicians and research}

Although the majority of research in this area is relatively new, empirical evidence indicates that the use of problem-focused coping strategies is related to improved HF outcomes, such as self-care, psychological well-being, and decreased mortality. Given that use of problem-focused coping strategies have been successful in other populations, such as diabetes mellitus ${ }^{[10,13]}$, end stage renal disease ${ }^{[11]}$, and multiple sclerosis ${ }^{[12]}$ in assisting adaptation to life changes associated with chronic illness, clinicians should assess for and consider using problem-focused coping strategies with their patients, such as planful problem-solving, identifying alternative solutions, and seeking social support to assist in coping with physical and psychological stressors associated with living with HF at each health care visit (see Table 2). Providing relevant and reliable information, both oral and written, about HF symptoms by nurses and other health providers, as well as discussing treatment options and their advantages and disadvantages are important so that patients feel they can take control of the unknown and decrease potentially stressful situations.

Even though experimental evidence is sparse, findings thus far illustrate the usefulness of stress management techniques to improve coping in HF. Based upon these findings, clinicians should consider incorporating stress management techniques (i.e., meditation, relaxation therapy, structured relaxation techniques) into patient education, as an optional coping strategy.

Lastly, better assessment of patients is recommended. Individuals with HF often have multiple co-morbid conditions which may exacerbate stress and make effective coping more difficult. These patients should be seen routinely in a clinic and assessed for signs of ineffective coping, such as depressive symptoms and anxiety. Individuals exhibiting evidence of psychological stress may need additional support in order to cope effectively with HF-related stressors ${ }^{[76]}$. Those patients exhibiting signs of psychological stress may need to be referred for further testing and treatment. Therefore, clinicians should assess and evaluate support needs at each visit to determine whether outside referrals for assistance are needed to support their physical and mental well-being. 
Table 2. Examples of how health providers may facilitate the use of problem-focused coping strategies by HF patients

Problem-Focused
Coping Strategies

Active Awareness

Cognitive Analysis

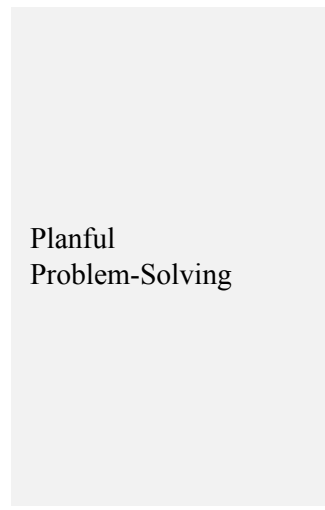

Seeking Social Support

Active Coping

Acceptance

\section{Examples}

Explore with patients situations in their daily lives that are stressful. This may include internal (e.g., HF

symptoms) as well as external stressors to them (interpersonal relationships).

"Tell me about how you spend your typical day."

"Describe for me people you enjoy being around or hobbies/activities that you really enjoy doing because they promote peaceful and good feelings."

"Describe people you are around or situations you are involved in, but had rather not be, because they are emotionally upsetting."

Explore with patients useful strategies for living with their HF diagnosis and associated symptoms and treatment regimens on a daily basis.

Allow adequate time for patients to deal with the reality of their HF diagnosis, supporting them both therapeutically, as well as emotionally.

Talk about how their HF can be managed, even though it can't be cured.

Discuss with patients how their lives are the same and different than from before their HF diagnosis.

Work with patients to understand that how they view their disease may affect their behaviors used to manage HF symptoms and treatment regimens.

"When you are faced with challenges, how do you usually react? Do you think you'll be able to handle them? Or do they make you feel overwhelmed?"

"When your symptoms are worse, what changes do you make to your usual activities?"

Explore with patients strategies that may be useful in dealing with HF symptoms and treatment regimens. Identify specific situations that are viewed as stressful (e.g., knowing what foods are lower in sodium, monitoring fluid status).

Identify what specifically is most stressful about these situations (e.g., they feel they can't enjoy eating foods and drinking fluids they previously enjoyed).

Identify 3-6 possible solutions to incorporate into their weekly schedules (e.g., obtaining a list of foods lower in sodium from a dietician or health provider; identifying a list of restaurants that would offer a reasonable selection of these foods; explore reliable sources of information regarding foods lower in sodium; make a list of foods that would not be good choices; read labels regarding sodium intake when they buy groceries at the grocery store; monitor weight daily at home).

Weigh the advantages and disadvantages of potential solutions.

Choose a solution they wish to implement first, second, third, etc.

Implement the specific solution (e.g., obtaining a list of foods lower in sodium from their dietician or health provider; monitoring daily weight).

Explore with HF patients strategies they may use to obtain instrumental support from their family, friends, and health providers.

Examine transportation options to the clinic, such scheduling return appointments the same day a friend is going to the clinic, identifying transportation sources through local churches, and calling the transportation system for transit schedules in their neighborhood.

Investigate how to obtain potential cost reductions in prescriptions through local pharmacies.

Identify potential sources to facilitate their completing ADLs and IADLs, such as going with friends to buy medication colored coded pill boxes to handle complex medication regimens, asking for assistance in setting up/establishing electronic bill payments; identifying names of people who could assist them with cleaning their house.

Offer HF patients information that allows them to make an informed decision on their own or encourages them to feel they have more control.

"These are acceptable treatment options that are available to you. Let's talk about the advantages and disadvantages of these different options as you decide what is best for you and your situation."

"You are doing what is right for you in handling ___ (e.g., your fatigue in the afternoon)."

Encourage HF patients to ask informational questions about their HF symptoms and treatment regimens.

"Do you have any questions I can answer related to your medications?"

"Do you have any questions I can answer related to symptoms you are experiencing?"

Encourage patients to seek support from their family, friends, and health providers.

"How are you feeling?"

"Do you have family or friends who support you emotionally?"

"Do you have family and friends with whom you can discuss how you are feeling?"

Explore with HF patients useful strategies to improve or lessen their HF-related symptoms.

Resting when they become fatigued.

Spacing ADLs and IADLs throughout the day.

Identifying situations in which it is more difficult to restrict their prescribed treatment regimen.

Notes. *There is overlap among these different coping strategies.

ADLs: Activities of Daily Living; IADLS: Instrumental Activities of Daily Living; HF: Heart Failure 
Further research is needed in several key areas to advance knowledge in this field of research. First, perhaps most vital to the progression of knowledge regarding coping in HF, as well as patient care, is the need for more longitudinal and experimental studies. Given that HF is a progressive disorder, individuals' coping requirements may change as HF-related stressors evolve and increase in intensity. Therefore, the evaluation of coping requirements and style over time is needed. Incorporating longitudinal designs into future studies will provide a better understanding of how individuals cope with a progressive disorder such as HF and subsequently provide information upon which to build interventions to improve HF-related outcomes across the progression of the disease process. Further, studies to identify the value of different types of emotion-focused coping, such as positive reappraisal, are needed. For example, can emotion-focused positive reappraisal be therapeutic in certain situations, such as when patients with HF have significant symptoms (e.g., extreme fatigue)? Also, given that depression and anxiety are closely related, often with an overlap of symptomatology, and that the majority of previous studies failed to differentiate between these two concepts, it will be important to make that distinction in future studies when examining these as outcome variables. Lastly, given that the majority of research in this area is correlational in nature, the direction of causality cannot be determined. For example, while it appears that the use of problem-focused coping strategies are associated with better HF-related outcomes, such as less psychological distress, it is also plausible that individuals experiencing less psychological distress will be better able to employ problem-focused coping strategies versus emotion-focused coping strategies.

Second, more experimental studies are needed. Thus far, experimental studies evaluating coping strategies have focused primarily on psychological well-being as an outcome, with a few studies also examining quality of life and physical/ functional status. Since evidence suggests a relationship between effective coping and self-care ${ }^{[42,56]}$ and that individuals with better self-care have fewer hospital readmissions and decreased mortality ${ }^{[71,77]}$, more experimental studies are needed to assess the efficacy of problem-focused coping strategies on self-care in this population. Likewise, longer intervention periods are needed with an increased number of contacts, as well as longer follow-up periods in order to strengthen and assess behavioral changes over time, as the disease progresses.

Third, researchers should strive to recruit samples that are representative of the target population, as the majority of samples used to investigate coping in HF have been comprised primarily of either Caucasian males or females. Few studies were found that included representative samples according to both gender and race. Also, the use of a conceptual/ theoretical framework is recommended when designing any research study ${ }^{[75]}$ and is considered an important component in intervention research design ${ }^{[78]}$.

Finally, the inclusion of hospital readmission and mortality rates as study outcomes is also recommended. Readmission and mortality rates are important indicators of effective self-care and will influence how health care professionals are reimbursed for HF-related care in the future. Currently, readmission and mortality rates are high for individuals with HF and create an economic burden on the patient as well as the health care industry ${ }^{[2,79]}$. Therefore, more research is necessary to determine whether coping interventions are effective in reducing readmission and mortality rates.

\section{Conclusion}

Effective coping is vital in successfully managing HF, including the associated physical symptoms and the psychological sequelae that may result ${ }^{[8,27,29,80]}$. However, individuals' cognitive appraisal, as well as factors such as co-morbid conditions, personality, and illness knowledge may influence coping style (i.e., problem-focused vs. emotionfocused) ${ }^{[21,38-40]}$. Given that, findings of this review suggest that problem-focused coping strategies may be more beneficial in assisting individuals in the coping process and are associated with positive HF outcomes, such as psychological well-being, self-care, and HRQoL ${ }^{[8,27,42,45]}$ as compared to emotion-focused coping strategies. Findings of this review also indicate that some emotion-focused strategies (e.g., denial and behavioral and mental disengagement ) may specifically be related to negative HF outcomes, such as psychological distress, decreased HRQoL, and HF-related 
mortality ${ }^{[14,15,17,27,29,63]}$. Considering this and previous work in other chronic illness populations ${ }^{[10-12]}$, nurses should contemplate including problem-focused coping strategies into patient and family education as a means to cope with HF.

Nursing research has contributed greatly to our understanding of the relationships between coping styles and HF outcomes, yet little experimental research exists investigating the effectiveness of problem-focused interventions. Therefore, more experimental research is needed in this area. Additionally, given that HF is a progressive disorder, future experimental studies should strive to include longitudinal designs so that the efficacy of problem-focused interventions throughout the progression of HF can be evaluated.

\section{References}

[1] Butler J. The management of heart failure. Pract Nurse. 2010; 21(6): 290-296.

[2] American Heart Association (AHA). Heart disease and stroke statistics-2013 update: A report from the American Heart Associaton. Circulation. 2013; 127: e6-e245. PMid:23239837 http://dx.doi.org/10.1161/CIR.0b013e31828124ad

[3] Liu F. Heart failure hospitalization rates rise among nation's seniors. http://www.newsroom.heart.org/index.php?s=45 (24 August 2010, date last accessed).

[4] Riegel B, Moser D, Anker S, Appel L, Dunbar S, Grady K, et al. State of the science: Promoting self-care in persons with heart failure. Circulation. 2009; 120(12): 1141-1163. PMid:19720935 http://dx.doi.org/10.1161/CIRCULATIONAHA.109.192628

[5] Thornhill K, Lyons AC, Nouwen A, Lip GYH. Experiences of living with congestive heart failure: A qualitative study. Brit J Health Psych. 2008; 13(1): 155-175. PMid:18230240 http://dx.doi.org/10.1348/135910706X170983

[6] Gottlieb SS, Khatta M, Friedmann E, Einbinder L, Katzen S, Baker B, et al. The influence of age, gender, and race on the prevalence of depression in heart failure patients. J Am Coll Cardiol. 2004; 43(9): 1542-1549. PMid:15120809 http://dx.doi.org/10.1016/j.jacc.2003.10.064

[7] Cully JA, Phillips LL, Kunik ME, Stanley MA, Deswal A. Predicting quality of life in veterans with heart failure: The role of disease severity, depression, and comorbid anxiety. Behav Med. 2010; 36(2): 70-76. PMid:20497945 http://dx.doi.org/10.1080/08964280903521297

[8] Dekker RL, Peden AR, Lennie TA, Schooler MP, Moser DK. Living with depressive symtpoms: Patients with heart failure. Am J Crit Care. 2009; 18(4): 310-318. PMid:19556409 http://dx.doi.org/10.4037/ajcc2009672

[9] Friedmann E, Thomas SA, Liu F, Morton PG, Chapa D, Gottlieb SS. Relationship of depression, anxiety, and social isolation to chronic heart failure outpatient mortality. Am Heart J. 2006; 152(5): 940e941-940e948.

[10] Karlsen B, Oftedal B, Bru E. The relationship between clinical indicators, coping styles, perceived support and diabetes-related distress among adults with type-2 diabetes. J Adv Nurs. 2012; 68(2): 391-401. PMid:21707728 http://dx.doi.org/10.1111/j.1365-2648.2011.05751.x

[11] Kristofferzon M., Lindqvist R, Nilsson A. Relationships between coping, coping resources and quality of life in patients with chronic illness: A pilot study. Scand J Psych. 2010; 25(3): 476-483.

[12] McCabe M, Stokes M, McDonald E. Changes in quality of life and coping among people with multiple sclerosis over a 2 year period. Psych Health Med. 2009; 14(1): 86-96. PMid:19085315 http://dx.doi.org/10.1080/13548500802017682

[13] Thoolen B, de Ridder D, Bensing J, Gorter K, Rutten G. Beyond good intentions: The role of proactive coping in achieving sustained behavioral change in the context of diabetes management. Psych Health. 2009; 24(3): 237-254. PMid:20204991 http://dx.doi.org/10.1080/08870440701864504

[14] Carels RA, Musher-Eizenman D, Cacciapaglia H, Perez-Benitez CI, Christie S, O’Brien W. Pyschological funtioning and physical symptoms in heart failure patients: A within individual approach. J Psychosom Res 2004; 56: 95-101. http://dx.doi.org/10.1016/S0022-3999(03)00041-2

[15] Doering LV, Dracup K, Caldwell MA, Moser DK, Erickson VS, Fonarow G, et al. Is coping style linked to emotional states in heart failure patients? J Card Fail. 2004; 10(4): 344-349. PMid:15309703 http://dx.doi.org/10.1016/j.cardfail.2003.10.001

[16] Gallagher R, Luttik ML, Jaarsma T. Social support and self-care in heart failure. J Cardiovasc Nurs. 2011; 26(6): 439-445. PMid:21372734 http://dx.doi.org/10.1097/JCN.0b013e31820984e1

[17] Murberg T, Furze G, Bru E. Avoidance coping styles predict mortality among patients with congestive heart failure: A 6-year follow-up study. Pers Indiv Differ. 2004; 36(4): 757-766. http://dx.doi.org/10.1016/S0191-8869(03)00130-2

[18] Rodriguez-Artalejo F, Guallar-Castillon P, Herrera MC, Otero CM, Chiva MO, Ochoa CC, et al. Social network as a predictor of hospital readmission and mortality among older patients wth heart failure. J Card Fail. 2006; 12(8): 621-627. PMid:17045181 http://dx.doi.org/10.1016/j.cardfail.2006.06.471

Published by Sciedu Press 
[19] Lazarus RS \& Folkman S. Stress, appraisal, and coping. New York: Springer Publishing Co, 1984.

[20] Lazarus RS \& Cohen JB. Environmental stress. In Human Behavior and the Environment: Current Theory and Research. I Altman and JF Wohlwill, eds. New York: Plenum, 1977. http://dx.doi.org/10.1007/978-1-4684-0808-9_3

[21] Cohen F. Coping. In Behavioral Health: A Handbook of Health Enhancement and Disease Prevention. JD Matarazzo, SM Weiss, JA Herd, NE Miller, \& SM Weiss, eds. New York: Wiley, 1984.

[22] Glanz K, Rimer BK, Lewis FM. Health behavior and health educaiton: Theory, research, and practice. San Fransico, CA: Wiley \& Sons, 2002.

[23] Lazarus RS. Coping theory and research: Past, present, and future. Psychosom Med 1993; 55: 234-247.

[24] Endler NS \& Parker JDA. Assessment of multidimensional coping: Task, emotion, and avoidance strategies. Psych Assess. 1994; 6(1): 50-60. http://dx.doi.org/10.1037/1040-3590.6.1.50

[25] Cornelius SW \& Caspi A. Everyday problem solving in adulthood and old age. Psychol Aging. 1987; $2(2)$ : $144-153$. PMid:3268204 http://dx.doi.org/10.1037/0882-7974.2.2.144

[26] Carver CS, Scheier MF, Weintraub JK. Assessing coping strategies: A theoretically based approach. J Pers Soc Psych. 1989; 56(2): 267-283. http://dx.doi.org/10.1037/0022-3514.56.2.267

[27] Vollman MW, LaMontagne LL, Hepworth JT. Coping and depressive symptoms in adults living with heart failure. J Cardiovasc Nurs. 2007; 22(2): 125-130. PMid:17318038 http://dx.doi.org/10.1097/00005082-200703000-00009

[28] Klein DM, Turvey CL, Pies CJ. Relationship of coping styles with quality of life and depressive symptoms in older heart failure patients. J Aging Health. 2007; 19(1): 22-38. PMid:17215200 http://dx.doi.org/10.1177/0898264306296398

[29] Trivedi RB, Blumenthal JA, O'Connor CM, Adams K, Hinderliter A, Dupree C, et al. Coping styles in heart failure patients with depressive symptoms. J Psychosom Res. 2009; 67(4): 339-346. PMid:19773027

http://dx.doi.org/10.1016/j.jpsychores.2009.05.014

[30] Fonarow G, Adams K, Abraham W, Yancy C, Boscardin W. Risk stratification for in-hospital mortality in acutely decompensated heart failure: Classification and regression tree analysis. JAMA. 2005; 293(5): 572-580. PMid:15687312 http://dx.doi.org/10.1001/jama.293.5.572

[31] Lien C, Gillespie N, Struthers D, McMurdo M. Heart failure in frail elderly patients: Diagnostic difficulties, co-morbidities, polypharmacy and treatment delimmas. Eur J Heart Fail 2002; 4(1): 91-98. http://dx.doi.org/10.1016/S1388-9842(01)00200-8

[32] Rich M. Heart failure in the elderly: Strategies to optimize outpatient control and reduce hospitalizations. Am J Geriatr Card. 2003; 12(1): 25-27. http://dx.doi.org/10.1111/j.1076-7460.2003.01752.x

[33] Friedman MM \& Quinn JR. Heart failure patients' time, symptoms, and actions before a hosptial admission. J Cardiovasc Nurs. 2008; 23(6): 506-512. PMid:18953214 http://dx.doi.org/10.1097/01.JCN.0000338928.51093.40

[34] Carlson B, Riegel B, Moser D. Self-care abilitites of patients with heart failure. Heart Lung. 2001; 30(5): 351-359. PMid:11604977 http://dx.doi.org/10.1067/mhl.2001.118611

[35] Murberg T \& Bru E. Coping and mortality among patients with congestive heart failure. Int J Behav Med. 2001 ; 8(1): 66-79. http://dx.doi.org/10.1207/S15327558IJBM0801_05

[36] Marusic A, Gudjonsson GH, Eysenck HJ, Starc R. Biological and psychological risk in ischemic heart disease: Empirical findings and a biopsychosocial model. Pers Indiv Diff. 1999; 26(2): 285-304. http://dx.doi.org/10.1016/S0191-8869(98)00132-9

[37] Suls J, David JP, Harvey JH. Personality and coping: three generations of research. J Pers 1996; 64(4): 711-735. PMid:8956512 http://dx.doi.org/10.1111/j.1467-6494.1996.tb00942.x

[38] Murberg T, Bru E, Stephens P. Personality and coping among congestive heart failure patients. Pers Indiv Differ. 2002; 32(5): 775-784. http://dx.doi.org/10.1016/S0191-8869(01)00081-2

[39] Hallas C, Wray J, Andreou P, Banner N. Depression and perceptions about heart failure predict quality of life in patients with advanced heart failure. Heart Lung. 2011; 40(2): 111-121. PMid:20561889 http://dx.doi.org/10.1016/j.hrtlng.2009.12.008

[40] Jackson J \& Emery C. Illness knowledge moderates the influence of coping style on quality of life among women with congestive heart failure. Heart Lung. 2011; 40(2): 122-129. PMid:20561886 http://dx.doi.org/10.1016/j.hrtlng.2009.12.005

[41] Nahlen C \& Saboonchi F. Coping, sense of coherece and the dimensions of affect in patients with chronic heart failure. Eur $\mathrm{J}$ Cardiovasc Nurs. 2010; 9(2): 118-125. PMid:20022304 http://dx.doi.org/10.1016/j.ejcnurse.2009.11.006

[42] Riegel B \& Carlson B. Facilitators and barriers to heart failure self-care. Patient Educ Couns. 2002; 46(4): $287-295$. http://dx.doi.org/10.1016/S0738-3991(01)00165-3

[43] Wu J, Moser D, Chung M, Lennie TA. Predictors of medication adherence using a multidimensional adherence model in patients with heart failure. J Card Fail 2008; 14(7): 603-614. PMid:18722327 http://dx.doi.org/10.1016/j.cardfail.2008.02.011

[44] Carels RA. The association between disease severity, functional status, depression and daily quality of life in congestive heart failure patients. Qual Life Res. 2004; 13(1): 63-72. PMid:15058788 http://dx.doi.org/10.1023/B:QURE.0000015301.58054.51 
[45] Park C, Fenster JR, Suresh DP, Bliss DE. Social support, appraisals, and coping as predictors of depression in congestive heart failure patients. Psychol Health. 2006; 21(6): 773-789. http://dx.doi.org/10.1080/14768320600682368

[46] Bosworth SJ, Steinhauser KE, Orr M, Lindqvist JH, Grambow, SC, Oddone EZ. Congestive heart failure patients' perceptions of quality of life: The integration of physical and psychosocial factors. Aging Ment Health. 2004; 8(1): 83-91. PMid:14690872 http://dx.doi.org/10.1080/13607860310001613374

[47] Heo S, Lennie TA, Okoli C, Moser DK. Quality of life in patients with heart failure. Ask the patients. Heart Lung 2009; 38(2): 100-108. PMid:19254628 http://dx.doi.org/10.1016/j.hrtlng.2008.04.002

[48] Wallis M, Boxer E, Grant S, Bardsley K, Carlson M, Lindqvist R. Health-related quality of life and coping in chronic illness: A pilot study. J Gen Int Med. 2000; 15(11): 769-789.

[49] Chiaranai C, Salyer J, Best A. Self-care and quality of life in patients with heart failure. Thai J Nurs Res. 2009; 13(4): $302-317$.

[50] Chriss PM, Sheposh J, Carlson B, Riegel B. Predictors of successful heart failure self-care maintenance in the first three months after hospitalization. Heart Lung. 2004; 33(6): 345-353. PMid:15597287 http://dx.doi.org/10.1016/j.hrtlng.2004.03.004

[51] Heo S, Moser D, Lennie TA, Riegel B, Chung, ML. Gender differencees in and factors related to self-care behaviors: A cross-sectional, correlational study of patients with heart failure. Int J Nurs Stud. 2008; 45(12): 1807-1815. PMid:18674762 http://dx.doi.org/10.1016/j.ijnurstu.2008.05.008

[52] Riegel B \& Carlson B. Is individual peer support a promising intervention for persons with heart failure? J Cardiovasc Nurs. 2004; 19(3): 174-183. PMid:15191260 http://dx.doi.org/10.1097/00005082-200405000-00006

[53] Riegel B, DicksonV, Kuhn L, Page K, Worrall-Carter L. Gender-specific barriers and facilitators to heart failure self-care: A mixed methods study. Int J Nurs Stud. 2010; 47: 888-895. PMid:20079902 http://dx.doi.org/10.1016/j.ijnurstu.2009.12.011

[54] Rockwell J \& Riegel B. Predictors of self-care in persons with heart failure. Heart Lung. 2001; 30(1): 18-25. PMid:11174364 http://dx.doi.org/10.1067/mhl.2001.112503

[55] Salyer J, Schubert CM, Chiaranai C. Supportive relationships, self-care confidence and heart failure self-care. J Cardiovasc Nurs. 2012; 27(5): 384-393. PMid:22048619 http://dx.doi.org/10.1097/JCN.0b013e31823228cd

[56] Sayers SL, Riegel B, Pawlowski S, Coyne JC, Samaha FF. Social support and self-care of patients with heart failure. Ann Behav Med 2008; 35: 70-79. http://dx.doi.org/10.1007/s12160-007-9003-x

[57] Tierney S, Elwers H, Sange C, Mamas M, Rutter MK, Gibson M, et al. What influences physical activity in people with heart failure? A qualitative study. Int J Nurs Stud 2011; 48(10), 1234-1243. doi: 10.1016/jijnurstu.2011.03.003

[58] Beck C \& Shah S. Research on health-related quality of life and cardiac conditions. Home Healthc Nurse. 2012; 30(1): 54-60. PMid:22173621 http://dx.doi.org/10.1097/NHH.0b013e31823aa740

[59] Eastwood J, Doering L, Roper J, Hays R. Uncertainty and health-related quality of life 1 year after coronary angiography. Am J Crit Care. 2008; 17(3): 232-242. PMid:18450680

[60] Graven LJ \& Grant JS. Coping and health-related quality of life in individuals with heart failure: An integrative review. Heart Lung. 2013; 42(3): 183-194. PMid:23312147 http://dx.doi.org/10.1016/j.hrtlng.2012.12.002

[61] Perez-Garcia AM, Olivan S, Bover R. Subjective well-being in heart failure patients: Influence of coping and depressive symptoms. Int J Behav Med, Epub April 19, 2013. PMid:23605558 http://dx.doi.org/10.1007/s12529-013-9311-4

[62] Park C, Malone M, Suresh DP, Bliss DE, Rosen R. Coping, meaning in life, and quality of life in congestive heart failure patients. Qual Life Res. 2008; 17(1): 21-26. PMid:18034319 http://dx.doi.org/10.1007/s11136-007-9279-0

[63] Bean MK, Gibson D, Flattery M, Duncan A, Hess M. Psychological factors, quality of life, and psychological distress: Ethnic differences in patients with heart failure. Prog Cardiovasc Nurs. 2009; 24(4): 131-140. PMid:20002337 http://dx.doi.org/10.1111/j.1751-7117.2009.00051.x

[64] Paukert AL, LeMaire A, Cully JA. Predictors of depressive symptoms in older veterans with heart failure. Aging Ment Health. 2009; 13(4): 601-610. PMid:19629786 http://dx.doi.org/10.1080/13607860802459823

[65] Allan R \& Fisher J. Heart and mind: The practice of cardiac psychology (2nd ed.) Washington DC: American Psycholgoical Association, 2011.

[66] Niles B, Silberbogen A, Klunk-Gillis J, Ryngala D, Paysnick A, Wolf E. Comparing mindfulness and psychoeducation treatments for combat-related PTSD using a telehealth approach. Psychol Trauma. 2012; 4(5): 538-547. http://dx.doi.org/10.1037/a0026161

[67] Luskin F, Reitz M, Newell K, Quinn TG, Haskell W. A controlled pilot study of stress management training of elderly patients with congestive heart failure. Prev Card. 2002; 5(4): 168-172, 176.

[68] Sullivan MJ, Wood L, Terry J, Brantley J, Charles A, McGee V, et al. The support, education, and research in chronic heart failure study (SEARCH): A mindfulness-based psychoeducational intervention improves depression and clinical symtpoms in patients with chronic heart failure. Am Heart J. 2009; 157(1): 84-90. PMid:19081401 http://dx.doi.org/10.1016/j.ahj.2008.08.033

[69] Yu D, Lee, D, Woo J. Improving health-related quality of life of patients with chronic heart failure: Effects of relaxation therapy. J Adv Nurs 2009; 66(2): 392-403. PMid:20423422 http://dx.doi.org/10.1111/j.1365-2648.2009.05198.x 
[70] Peveler R \& Johnston D. Subjective and cognitive effects of relaxation. Behav Res Ther. 1986; 24(4): 413-420. http://dx.doi.org/10.1016/0005-7967(86)90006-9

[71] Murberg T \& Bru E. Social relationships and mortality in patients with congestive heart failure. J Psychosom Res. 2001; 51: 521-527. http://dx.doi.org/10.1016/S0022-3999(01)00226-4

[72] Anxiety \& Depression Association of America. Understanding the facts. http://www.adaa.org/ (12 May 2013, date last accessed).

[73] Shadish W, Cook T, Campbell D. Experimental and quasi-experimental designs for generalized causal inference. Boston, MA: Houghton Mifflin Company, 2002. PMid:11928889

[74] Emory Healthcare. Heart failure statistics http://emoryhealthcare.org/heart-failure/learn-about-heart-failure/statistics.html. (18 February 2013, date last accessed).

[75] Polit D \& Beck C. Nursing research: Generating and assessing evidece for nursing practice (9th ed). Philadelphia, PA: Lippincott, Willimas, \& Wilkins, 2012.

[76] Holahan CJ, Holahan CK, Moos RH, Brennan PL. Social context, coping strategies, and depressive symptoms. An expanded model with cardiac patients. J Pers Soc Psych. 1997; 72(4): 918-928. http://dx.doi.org/10.1037/0022-3514.72.4.918

[77] Lee C, Moser D, Lennie TA, Riegel B. Event-free survival in adults with heart failure who engage in self-care management. Heart Lung 2011: 40(1): 12-20. PMid:20561885 http://dx.doi.org/10.1016/j.hrtlng.2009.12.003

[78] Sidani S \& Braden CJ. Evaluating nursing interventions: A theory-driven approach. Thousand Oaks, CA: Sage, 1998.

[79] Aranda JM, Johnson JW, Conti JB. Current trends in heart failure readmission rates: Analysis of Medicare data. Clin Card. 2009; 32(1): 47-52. PMid:19143005 http://dx.doi.org/10.1002/clc.20453

[80] Piamjariyakul U, Smith CE, Werkowitch M, Elyachar A. Part I: Heart failure home management: patients, multidisciplinary health care professionals and family caregivers' perspectives. App Nurs Res. 2012: 25(4): 239-245. PMid:21741211

http://dx.doi.org/10.1016/j.apnr.2011.05.001 